FEATURE ARTICLE

\title{
Turbulence, Perturbance, and Educational Change
}

\author{
BRIAN R. BEABOUT \\ University of New Orleans (USA)
}

\begin{abstract}
While scholarship on educational change has long accepted that disruptions to the status quo are an essential part of the change process, disruption has never been more central to planned change than it is in the current political context in the USA, where legislation has mandated school closure, reconstitution, and turnaround as required remedies for schools failing to produce annual student achievement gains required by government. We are also unfortunately hampered by the imprecise language that surrounds complexity-based theories of educational change. Words such as perturbance, turbulence, and disruption all have gained currency lately, but meanings are unclear and overlapping. This essay seeks to lend some clarity to the debate by defining turbulence as the perception of forces in an organizational environment with the potential to disrupt current modes of operation. This is distinguished from perturbance which is defined as the social process of actors coming together to adjust organizational practice to fit with the changing environmental context. The case is argued that sensible reformers ought to be fostering perturbance while minimizing the harmful consequences of excessive turbulence.
\end{abstract}

\section{Introduction}

This essay seeks to clarify the language of complexity-influenced educational change as this area of research continues its maturation. There has long been an interest in disruption of the status quo as a key component in the process of organizational change (Christensen, 1997; Ely, 1976; Fullan, 1999, 2001; Morrison, 2002; McQuillan, 2008). Outside of education, economist Milton Friedman has stated that "only a crisis- actual or perceived- produces real change" (1962, p. ix). This single statement asks us (importantly) to attend both to disruptions and to how they are perceived. Educational change scholar Michael Fullan has written that "when things are unsettled, we can find new ways to move ahead and to create breakthroughs not possible in stagnant societies" (2001, p. 1). More recently, US Secretary of Education Arne Duncan has offered his policy of intentional disruption via reconstitution and school takeovers as an approach to reform in persistently failing schools (Harris, 2010). In these recent educational reform policies, we see disruption not only as an uncontrollable, unforeseeable event like an earthquake, but as a clear first-choice option for implementing change. The wisdom of such an approach is less clear, however, and the discussion below will argue the case that reformers ought to emphasize the social process of perturbance rather than the structural/environmental focus of turbulence. 


\section{"Shake the cage"}

Once, during an interview for a teaching job in an urban district, I was asked by the superintendent to "go in there and shake the cage - wake those teachers up" with hopes that my noisy behavior would improve a low-performing middle school's English department. I was not asked about how I might work with the existing staff to build up their skills sets or improve curricular alignment, but merely to "wake them up." I was surprised that the reform-minded district continued to employ so many sleep-deprived teachers. This conversation points to both the strong desire for educational change in many urban districts, and a lack of expertise in how to go about doing it. This paper seeks to refine the language of educational change in hopes that clearer language can give rise to clearer thinking and action.

The central assumption of the argument for change-by-disruption is that a significant disruption in work conditions or processes will lead to changed (and presumably better) performance. This promising notion should be tempered, however, by the overwhelming empirical evidence showing that disruptions alone are not very effective at fostering positive change in schools (Berman \& McLaughlin, 1975; Cuban, 2001; Hubbard, Mehan \& Stein, 2006; McLaughlin, 1990; Tye, 2000). Understanding that school change necessitates change in instructional practice, Elmore and Burney's (1999) requirements for change are more empirically justifiable:

Change in instructional practice involves working through problems of practice with peers and experts, observations of practice, and steady accumulation over time of new practices anchored in one's own classroom setting. (p. 276)

This approach to change is significantly more focused on relationships, learning, and context, all of which are central to complexity-influenced models of educational change (Duffy, 2003; Fullan, 2001; Lemke \& Sabelli, 2008; Reigeluth, 2006; Sirotnik, 2005). These complexity-based models do not preclude significant disruption; in fact disruption can have a useful role. However emphasis should be placed on the resolution of disruptions rather than on the disruptions themselves. Part of why the disruption itself is not so important is that schools and classrooms provide significant disruptions all on their own. Dealing with these constant disruptive forces is, in fact, part of why schools are so resistant to change (Sarason, 1982). Teaching is a profession with much unpredictability: the daily moods of 30 young people (and teachers and staff), the constant physical and emotional development of young people (and teachers and staff), and curriculum and assessments that change with the political winds. In such a scenario, holding tight to teaching methods as the one controllable variable is an understandable human response (Evans, 1996). At the school level, there are an equal number of highly variable forces: district budget cuts, changing student demographics, catching up with deferred building maintenance, teacher and leadership turnover, etc. Combining these relatively unpredictable forces with the new state-enacted reform-by-disruption policies encapsulated in most standards-based accountability schemes, one might reasonable ask if our schools need more or less crisis in order to better meet public demands. It is here where several core ideas from chaos and complexity literature can be helpful to the thinking of educators and researchers.

\section{Defining turbulence and perturbance}

All of the disturbances listed above are a common part of schools when defined as systems nested within the larger social, cultural, and political systems of a population (Carr, 1997). They are more or less permanent contexts of the work of schools. When forces are perceived that have the potential to impact the school in important ways, we can say that the school is experiencing turbulence. Turbulence is the creation of increased 
uncertainty - a term also familiar to complexitivists and a central feature of educating young people. Note here that turbulence is not necessarily denoted by measurable changes in environmental conditions, just a human perception of this possibility. As Gross (1998) writes in his book on leading curriculum change:

Anyone who has flown knows that turbulence is an unstable condition. Gone is that smooth-as-glass feeling of flight. It is replaced with slight bumps, the seat belt sign going on, and a small dread feeling that things might get much rockier soon. (p. 113)

Fans of the American television show Lost may find this airplane reference a familiar image. The sweaty-palms and increased heart-rate of the nervous air traveler is not unlike a physiological response a new teacher might feel upon hearing that a troubled student was returning from suspension, or when attending the first faculty meeting under a new, and unknown, school principal. People are on edge, and want, more than almost anything, a return to the predictable, stable existence of yesterday. Of course, neither plane rides nor schools are ever really predictable. Uncertainty is part and parcel of the experience. Our discomfort with change and our fear of the unknown merely create a fictional, stable past that never really existed.

Nonetheless, the onset of turbulence, in which change is likely but outcomes unknown, is of great interest to complexity-influenced scholars of change. This moment, on the "edge-of-chaos" (Pascale, Millemann \& Gioja, 2000) is both frightening and dynamic: the future is uncertain, the potential for change is great, but treasured relationships and access to valued resources may be challenged. Turbulence brings us to this point, and from there group processes determine a collective response.

Turbulence is not something we humans enjoy experiencing alone. In one Lost episode, the character Jack reaches out to hold hands with another passenger when their trans-oceanic flight experiences some significant turbulence. Responding to turbulence is, almost instinctively, a social process for humans. When we do not know what is coming next, we look at each other and ask, "What's next?" This turning to each other without certainty is perhaps the pregnant seed of all social change. When current structures are in doubt, people engage with one another and make decisions together about what to do. As applied to organizational life, this collaborative process of people coming together to answer the question, "What's next?" is what I will call perturbance. And so educational change from a complexitivist lens might be theorized as this cycle of turbulence and perturbance as disruptions are perceived and then either ignored or responded to by communities of shared practice.

In the remainder of this paper, I examine the literature and develop these concepts of structural/environmental turbulence with socially-mediated perturbance. To explore these two related concepts, I draw from the theoretical literature as well as scholarship on organizational and educational change. I make the case that sustainable educational reform requires ensuring productive perturbance while minimizing the effects of excessive turbulence on our schools. I distinguish between the words turbulence and perturbance by defining turbulence as the perception of potentially disruptive forces in an organization's environment or operating conditions and perturbance as a social process in which people respond to turbulence by considering organizational practice. As such, it is possible to have turbulence that does not become a perturbance if it is not processed by people. There are multiple sources of turbulence, and the wisest among us know which turbulence to attend to and which to ignore (Fullan, 2000) - and even they are often wrong. People can ignore turbulence or can attend to it in superficial ways without implicating organizational practice, and thus the system remains unperturbed. If a school has a dramatic rise in the number of English language learners but does nothing to the structure of curriculum to address this, it has experienced turbulence but not perturbance. This distinction does not preclude change with internal origins. In this case, turbulence is perceived by individuals or sub-groups within the school, and perturbance 
occurs if these concerns are taken up by other members in ways that call into question organizational practice. See the section below on internal turbulence for more of this discussion.

It is also important to note, at the outset, that this paper deals with metaphorical applications of complexity theory to the social institution of the school. I do not make claims here based on direct application the mathematical field of nonlinear dynamics, and the challenges in applying a theory metaphorically rather than directly are certainly a risk this paper takes (Polley, 1997). In particular, the terms perturbance and turbulence have entirely different meanings in physics. I recognize the potential for confusion, but view the benefit of more linguistic clarity in our social science field as reason enough to take this risk.

\section{Chaos and complexity theories and the schools}

This paper draws on applications of chaos theory and complexity theory to the study of school reform. While many of these ideas first surfaced in the hard sciences (see Alhadeff-Jones, 2008; Briggs \& Peat, 1999; Prigogine \& Stengers, 1984), these theories have been increasingly applied to the social sciences, including education (CarrChellman, 2000; Davis, 2008; Mason, 2008; Maxcy, 1995; Morrison, 2002; Reigeluth, 2004; Wheatley, 1999). Wheatley, (1999) explains that "a system can descend into chaos and unpredictability, yet within that state of chaos the system is held within boundaries that are well-ordered and predictable" (p. 13). The identification of such well-ordered, but often hidden, boundaries of school systems is an area where complexity research can make a significant contribution. As complex adaptive systems (Briggs \& Peat, 1989), schools are systems in which all parts of a given system affect one another, and where changes in one part of a system often cause unpredictable effects in other parts (Reigeluth, 2004).

This property of complex systems has been a problematic aspect of school reformers for over a generation, leading Seymour Sarason to talk about the "intractability of schools to educational reform" (1990, p. 147). It is precisely this challenge of complex cause-effect relationships (Lemke \& Sabelli, 2008) that makes planned turbulence troublesome as a reform strategy. While it may certainly disrupt educational practice, our uncertainty about a school's responses to turbulence means that the school is equally likely to get worse post-turbulence as it is to make productive change. Doing nothing may produce similar results without the attendant psychological trauma. A number of researchers have documented this phenomenon. Fink (2003) tracks the decline of a formerly excellent high school during Ontario's standards-based reform movement. Beabout (2010) reports the challenges principals in New Orleans had in rebuilding their schools in the massively decentralized post-Katrina period. Perhaps most illustrative, Ravitch (2010) details the experiences of educators in San Diego's public schools under the leadership of Alan Bersin and Anthony Alvarado, whose reform program has been labeled with the motto "1) Do it fast, 2) Do it deep, 3) Take no prisoners" (p. 53). Their reforms clearly were a case of intentional internal turbulence, but there was no little room for dialogic interaction, and their results were mixed.

It should not be necessary to state this, but schools do not always flourish under conditions of turbulence, intentional or otherwise. Many current school reformers seem to take turbulence-creation as an assumed first step. This is misguided and often premature. Reformers should be thoughtfully creating the conditions by which perturbance occurs. This is a human-centered conception of change (Jörg, 1999), rather than a program or management-centered one. It is also a conception where change is slow and unpredictable rather than instantaneous and planned (Fullan, 2001).

By beginning with an assumption that schools are complex systems, prone to unpredictable turbulence, the conceptual tools provided by chaos and complexity 
theories provide a vocabulary with which to build new knowledge about the dynamics of educational change. Continuous learning by groups of educators is essential for sustainable improvement. This notion of organizational learning on the part of educators is a significant area of inquiry in the educational change research (Elmore \& Burney, 1999; McLaughlin \& Talbert, 2001; Stein, Hubbard \& Mehan, 2004), and one which I will relate to perturbance. Both processes are collective, unpredictable in outcomes, and require the creation of conditions rather than dictated outcomes or procedures (Datnow, 2011; Hargreaves, 1994). The following discussion of the educational change literature underscores these connections between organizational learning in the field of educational change and the complexity related terms of turbulence and perturbance.

\section{Perturbance and organizational learning}

Recent scholarship has begun to identify gaps in our ardent belief in linear, deterministic processes of educational change. These deterministic processes are broadly characterized by the identification by experts of gaps between current and preferred performance, ensuing with strategic plans drawn up by consultants, and dutifully implemented by teachers. Complexitivist scholars have identified such linear thinking as a philosophical blind spot for which there is no well-developed alternative paradigm (Jörg, 2009). This corroborates the rather unimpressive effects of nearly sixty years of uninterrupted educational reform movements in the democracies of the west (Ravitch, 2000). Scholars of change employing complexity have argued for a refocusing of change efforts on the conditions that facilitate change rather than the specific processes or outcomes typical of most proposals for reform (Fullan, 2001; Osberg, 2005). The dialogic interactions of educators in some shared space lead to a consideration of current levels of performance and preferred outcomes, not in deterministic ways that dismiss the uniqueness of participating individuals and the inherent differences between geographic communities, but in an emergent way that takes local wishes, capacities, and challenges into account. This is a theory of change centered on the authentic human experiences of educators serving real, unique human communities.

Over the last 30 years, scholars of educational change have identified a number of readiness factors that increase the chances that a particular change effort will succeedwe might think of these as conditions contributing to perturbance. Among these are: dissatisfaction with the status quo, proven leadership, financial stability, time and resources for change (Ely, 1976; Nias, Southworth \& Campbell, 1992). Perhaps the most important result of this inquiry into the conditions that facilitate change is the concept of the learning organization. Jörg (1999) identifies learning through interaction as the central element to a programmatic understanding of educational complexity; a key component of complexity-informed educational change is educators engaging in sustained interactions to address shared problems.

Senge (1990) defines learning organizations as ones that focus on building the capacity of individuals and teams and creating new ways for socially distributed learning to interface with organizational purposes and practices. The concept of the learning organization has made inroads into the educational reform literature both in explicit application (Fullan, 2001; Morrison, 2002; Reigeluth, 2004; Senge et al., 2000) as well as in reform models based on local contexts and teacher ownership (Meier, 2001; Oakes \& Lipton, 2002) in lieu of externally developed reform models (Mclaughlin \& Mitra, 2001; Ravitch, 2000; Reigeluth, Carr-Chellman, Beabout \& Watson, 2006). Meier (2002) discusses replacing the dominant "adopt-a-program" approach to school reform with teacher responsibility, experimentation, collaboration, critique, and meaningful accountability: 
The habit of falling back on excuses - "I had to," "That's the way it's supposed to be" can only be rooted out by major surgery. It will be painful, and it won't all come out at once... There must be some kind of combination of discomfiture and support - focused always on what does and does not have an impact on children's learning. (p. 143)

This language tying improvement to discomfort is well-aligned with the turbulenceperturbance cycle described here. Notice that this is a hybrid approach. There is as much attention given to the process of teacher response as there is to the turbulence created. This is in line with Mainzer's view that ethical human systems seek to "...find the balance between self-organization, control, and governance of complex systems in order to support a sustainable future of mankind [sic]" (2009, p. 23). Similarly, Morin (1999) notes that such thoughtful action lies at the intersection of acting in ignorance and not acting at all (the risk-caution loop). In Meier's case, she does not use complexitivist language, but her stance as a school principal was to invite her staff into fostered dialogue about their habit of abdicating their responsibility as professionals to continuously improve their practice. Meier's book describes the ways in which her school thoughtfully included teacher dialogue, risk-taking, and critique into the fabric of teachers' professional lives. Intentional turbulence was used, but only after a strong foundation supporting the social process of perturbance has been built.

Learning organizations require both the cultural conditions that support professional learning (see Fullan, 2001; Hubbard, Mehan \& Stein, 2006) as well as information that educators can learn with (other educators, readings, student performance data, etc.). Given the joint forces of high-stakes testing and increased electronic access to performance data and published research on the subject, it is hard to imagine much effort is required to find data for schools with which to engage. Most Western schools are awash in data and the most challenging aspect of organizational learning is likely determining which of the myriad sources of data are worth expenditures of valuable time. Data can be a good source of turbulence when it is broadly perceived as accurate and important.

To change in ways that are attuned with perturbance, schools must take raw data and convert it into usable knowledge that can be the foundation for changed practice. This data must be translated into common language that is shared by a faculty and its diverse internal networks (Fullan, 2001; Morrison, 2002). Incentivizing the sharing of knowledge has been a commonly suggested approach for catalyzing this transformative process, but it has not seen wide success in educational environments. Given the long history of teacher isolation in Western societies (Little, 1990; Lortie, 1975) it is not surprising that official mandates for professional learning have often led to contrived collegiality (Hargreaves, 1994; Hargreaves \& Shirley, 2008), not true collaboration. A school that can engage in perturbance requires specific cultural conditions that promote collaboration among teachers in solving the problems of practice. These cultural traits are described next.

This educational change literature stresses the need for successful school change to focus on developing a school culture that fosters trust (Bryk \& Schneider, 2002), experimentation, and true collegiality (Olsen \& Kirtman, 2002). If, as Elmore and Burney suggest, changing instruction (and thus schooling) is a collaborative, social process, then this area of work on learning organizations can be seen as an important ground for moving beyond perceiving turbulence to socially-mediated perturbance. While all schools encounter turbulence, only those that posses the culture of a learning organization can use this disruption to examine their practice and institute sustainable change. This is the process of perturbance. Akin to the oyster creating a pearl out of an unwelcome grain of sand, a school with a deep sense of collective responsibility (Newmann \& Wehalge, 1995), a healthy forum for dialogue and critique (Nathan, 2009), and trust in the professional abilities of teachers is able to perceive turbulence and make informed decisions about "what's next." 


\section{Fleshing out the meanings of perturbance and turbulence}

In order to develop the definitions of perturbance and turbulence given above, it may be helpful to illustrate them with concrete examples from the literature and a more nuanced discussion of their features and uses. An essential understanding is that while turbulence can be both planned and unplanned, perturbance can only be an intentional phenomenon. Also instructive is the chronological order of turbulence and perturbance. Perturbance requires turbulence, although the sources for turbulence are varied and can be both internal and/or external as well as planned or unplanned. Collaborative work that examines a school's external environment and internal functions and relates them to that school's purposes never happens without effort. It is hard (and thoughtful) work that must be sustained by leadership, supported with time and resources, and can only happen in a climate where risk-taking, support, and collaborative learning exist. The following sections provide a discussion of unintentional turbulence, intentional turbulence, and the turbulence/perturbance lifecycle.

\section{Unintentional turbulence}

Necessity can be the mother of invention. Much has been written about the seemingly unpredictable maelstroms organizations operate under and their brave (and sometimes comical) attempts to steer through them. In fact, planning and sustainability are key areas of research in the complexity-paradigm. Peter Drucker, the renowned management theorist has written:

... the one certainty about the times ahead, the times in which managers will have to work and to perform, is that they will be turbulent times. And in turbulent times, the first task of management is to make sure of the institution's capacity for survival, to make sure of its structural strength and soundness, of its capacity to survive a blow, to adapt to sudden change, and to avail itself of new opportunities. (1980, p.1)

This defensive and reactive sounding advice casts turbulence in a rather negative light and flies in the face of more recent reform-by-turbulence policies in which educational authorities have unleashed turbulence intentionally. Nonetheless, unintended turbulence can be a change agent.

In his edited volume on conflict and school change, Milstein (1980) reflects on the growing discontent with schools throughout the socially turbulent 1960s and 1970s in the USA and provides some analysis that is useful here. He defines conflict as "a situation that evolves when individuals, groups, or even organizations believe that their interests are incompatible" (p.6). What is the difference between turbulence and conflict? In focusing on conflict, he focuses on instances of turbulence in which other people or groups alter a school's operating conditions. Conflict is described as a people-people interaction. This excludes other causes of turbulence for a school: performance, curriculum change, policy change, etc. Nonetheless, turbulence can be thought of as the perception of a potential conflict.

In the same volume, Chesler, Crowfoot, and Bryant (1980) distinguish long-standing conflict (as a result of social inequality) from crisis: when "this natural contest may, at times, become rancorous or turbulent in ways that threaten the social fabric and cause personal pain for many or all citizens" (p.30). Crisis here is taken to mean temporary uprisings that threaten an entire society, its schools, economic system, and political arrangements. While this type of macro-level crisis certainly falls under my definition of turbulence, I will also include forces that might threaten a school's identity (language policies that run counter to a school's mission) or a school's existence (loss of students) but might leave society as a whole relatively intact. Some turbulence portends great disruption for certain groups while very little for others. See the section below on turbulence in nested systems for more on this issue. 
In the realm of educational scholarship, turbulence theory (Gross, 1998, 2004) may provide some clarity on the matter of unintentional turbulence in educational change. In Gross's theory, developed out of his study of curricular change in schools, turbulence is demarcated with the simple terms of: light, moderate, severe, and extreme. Light turbulence signifies an issue that requires some attention, but poses little threat to the school system's functioning. Moderate turbulence poses measurable challenges to the system, and must be addressed in some way so that the school can continue to function. Severe turbulence is a strong disruption to the school system that could lead to collapse if immediate action is not taken. Since Gross' (1998) study examined curriculum reform, he applied the extreme turbulence label to places in which a reform project had been abandoned altogether. In this instance, I might extend his meaning to the broader arena of system reform and apply extreme turbulence to cases in which schools or school systems ceased to operate. Cases such as war, massive political revolution, and natural disaster would qualify here. Gross' (1998) study deals only with unintended turbulence and advocates a collaborative problem-solving approach to dealing with it. Germaine to the present discussion is his suggestion that under "severe" turbulence, a recommended strategy is to "be prepared for the birth of new possibilities and an altered organization" (p.133). Lower levels of turbulence bring about incremental, tinkering change while higher levels of turbulence can bring about more radical change. Gross suggests that responses to turbulence of all levels however, should include involving diverse constituencies in dialogue about current conditions and preferred future conditions. While Gross does not use the term, I would call this process perturbance. What is missing in Gross's discussion is guidance on what types of turbulence ought to be attended to and which ought to be ignored. His focus strictly on the strength of turbulence paints only a partial picture. This is emblematic of our misplaced emphasis on turbulence instead of perturbance.

Gross' typology might be compared to the classic causal textures framework of Emery and Trist (1965). They classify organizational environments on a scale of increasing turbulence as: placid, disturbed-reactive, and turbulent. In this model, the regular vagaries of institutional life and the evolving competitive marketplace make up the first two levels of the typology. It is only when significant change from outside an organization's normal operating environment impinges and threatens to change the rules of the game that the word turbulence is used. In both Gross' and Emery and Trist's models, turbulence is described as a difficult-(or impossible)to-predict outside force. And while responding to such unintentional turbulence can bring about perturbance and change, it is not described as a strategy for planned change, as it is in the next discussion on intentional turbulence.

\section{Intentional turbulence}

While the above discussion focuses on organizational change as a response to relatively unpredictable (or at least unintentional) environmental changes, we now turn to instances in which turbulence is intentionally unleashed on an organization to spur change. I take up, in turn, intentional turbulence, turbulence and opportunism, and selfturbulence. Much of the turbulence-as-reform rhetoric in school change is based on the systems theory concept of equilibrium. A system is at equilibrium when it reaches a state of maximum entropy (disorder) and energy flow ceases (Briggs \& Peat, 1989). Those who apply chaos and complexity theories to social systems conceptualize it in one of two ways.

The first understanding is equilibrium as death (Wheatley, 1999). This can describe a social system when there is no flow of resources, energy, or ideas. Unless a system interacts with its environment, it has no purpose, it ceases to get the resources it needs, and thus it eventually dies. In practical application, one might envision schools which 
isolate themselves from their communities (via overly bureaucratic governance, avoiding parental engagement, and/or only serving certain portions of the community) and therefore do not alter processes based on changes in the environment. They may produce in students an inability to provide for their families; these schools may also contribute to social decline. While tension builds between the school system and its environment, the system continues along its current path, either unwilling or unable to alter practice in a way that will reduce the tension with its environment. In essence, this is a false equilibrium in which internal processes remain unchanged despite mounting evidence that current relationships are unsustainable.

On the other hand, equilibrium in social systems has also been described as a homeostatic system (Hutchins, 1996). This describes a living system that is alive, where processes are occurring, but not changing significantly. Briggs and Peat (1989) describe such systems as near-to-equilibrium systems. We might conceive of such systems as those in which the external environment is generally satisfied with the performance of the school system, and continues to provide necessary resources that allow for the continuation of current levels of school functioning. These systems are more open and are more amenable to small adjustments in practice than those described above. As a practical example, a school that is operating according to the wishes of the local community is likely to fall into this category. Alan Peshkin's (1978) ethnography of a school district in rural America describes such a system. Here, the school board sees its job as ensuring that most students will "stick around" and not get "too talented" that they end up contributing to the population decline characteristic of much of rural America by leaving "town." Homeostatic school systems could be said to exist in a peaceful alignment of school performance and community wishes, although optimal performance is by no means guaranteed.

Those who seek change via turbulence seek to intentionally break this equilibrium between school and local community, often by imposing outcome standards in hopes of fostering change that will better align the organization with broad environmental conditions rather than local ones. To be blunt, national policymakers are more interested in generating more college graduates than they are in maintaining a viable population in Peshkin's agricultural town.

A number of scholars (with or without explicit reference to chaos and complexity theories) point to intentionally disturbing an organization's equilibrium as a change strategy. Wheatley (1999, p. 108) describes managers as "equilibrium busters" that "provoke," "disrupt," and "stir things up," to create change - not unlike the superintendant that wanted me to "shake the cage." Briggs and Peat (1989) describe farfrom-equilibrium systems on which "systems don't just break down, [but] new systems emerge" (p. 136). Based on the discussion above, this might be seen as disrupting broken communication patterns between a school and its immediate environment or disrupting broken communication between a local community and perceived broader regional or national needs. This image of disruption is certainly a liberating and fresh message for school leaders who often feel encumbered by tasks that are Sisyphusian in scope.

But hidden in Wheatley's (1999) tale, here is a subtle detail that is not fully developed: "there is more than enough confusion and ambiguity in our lives to work with. We don't have to worry about creating more, only about how to work more artfully with what we already have" (p. 108). This qualification changes everything that the casual reader might take away from her previous image of managers as freewheeling equilibrium busters. If equilibrium busting really entails making artful decisions about which challenges and ambiguities ought to be attended to, then the knowledge base of learning organizations described above is implicated directly. In fact, a primary lesson from this literature is that learning can come from anywhere in an organization, so it is not just managers that ought to be responsible for provoking and questioning, but every member of the group. 
Regardless of the source, change by intentional disruption is a well-documented strategy. Selsky and McCann (2008) discuss intentional attempts to "jolt" a field with the introduction of new policies or technologies as one of the primary causes of contextual disruptions for organizations. Pacale, Milleman and Gioja (2000) describe the organization-wide conversations held to generate substantive dialogue between executives and store employees at Sears. While these conversations used learning maps that were developed by upper management, I cannot help but recognize the similarities between this "disruptive" practice and Freire's (2000) use of visuals to create generative themes in his adult literacy initiatives in Brazil. Ravitch (2010) describes the full-scale assault on the San Diego Public Schools orchestrated by the Alan Bersin administration. In this case, the disruption was a highly bureaucratic installation of preferred teaching practices and social relations among educators. But like any less specific turbulence, it made maintenance of the status quo very difficult. In any case, both of the above cases involve intentional turbulence being used to bring about change. Intentional turbulence can involve consensus-based change processes as well as conflict-based ones (Milstein, 1980).

\section{Turbulence and opportunism}

This discussion of intentional turbulence as a change strategy also must include reference to the related strategy of change-by-opportunism. In this case, turbulence is not unleashed on organizations intentionally, but reformers lie in wait with reforms, political support, and financing. When extreme turbulence strikes, they quickly "shock" the system with these united forces and institutionalize these quickly adopted changes. Both Klein (2007) and Beabout (2007) describe the effectiveness with which charter school and school choice advocates were able to rapidly restructure public schooling in New Orleans during the turbulence that filled the final months of 2005 after Hurricane Katrina. This change-by-opportunism approach does not create turbulence for the systems it wishes to change, but it co-opts this turbulence to institute changes desired by a certain group. This strategy bypasses the process of perturbance and moves immediately from turbulence to a new system state without the dialogical examination of system practice in response to turbulence. Rapid change occurs, but without the process of people asking each other "Now what?" between turbulence and organizational response.

While the results of school reform in post-Katrina New Orleans are uncertain, there is both demonstrated academic improvement (Perry \& Schwam-Baird, 2010) as well as significant public resistance to many of the recent changes (Buras, 2010; Chang, 2010). Despite the obvious ethical questions surrounding change-by-opportunism, there should also be concern that while this strategy might lead to successful structural change in the short term, a lack of broad participation may lead to long-term resistance and rejection or co-optation of hurriedly adopted reforms.

\section{Self-turbulence}

So the role of turbulence in educational change is somewhat clearer. But what if long periods go by without significant turbulence in a school's environment? Or what if the only type of turbulence that appears is extreme turbulence that does not support sustainable change? These questions make it reasonable to suggest the idea of selfturbulence. Since turbulence is defined as a force from the environment, it can be somewhat unpredictable. To make the benefits of perturbance somewhat more regular and predictable, it seems prudent for schools and other organizations to set aside collaborative time that has as its explicit purpose an examination of the goals and practices of the group based on the recent experiences of individual members. These gatherings create turbulence as potentially disruptive forces. The group can decide 
where to take action. These are meetings or retreats in which predictable memoranda and administrivia are tossed aside and a broader discussion about the purposes and performance of the group takes place. Given the intensity of teachers' work lives (Hargreaves, 1994), creating a social space for the consideration of the broader purposes of education is no small task. Suggestions might include using an off-site facility, having special food or drinks, timing the self-turbulence meetings so that teachers are able to dedicate the emotional energy required, and inviting a small but diverse group of staff to participate.

Such self-turbulence activities are really an invitation for turbulence to emerge, as it is quite possible that a discussion on organizational performance and environmental needs results in only small areas of improvement and not fundamental changes. But a regular diet of such invitations, within the required learning culture, is likely to keep the school from becoming out of touch with its environment.

\section{The turbulence/ perturbance lifecycle}

There is a much shorter and shallower base of social science literature for the term perturbance than there is for turbulence. It is therefore necessary to spend time building the case for perturbance logically, while incorporating the scant literature where appropriate. Reigeluth (2006) uses perturbance to refer to "any change in a system's environment that causes disequilibrium" (p. 45). Accepting this definition, perturbance becomes a subset of turbulence consisting only of those forces that lead a system to disequilibrium. While the link between perturbance and disequilibrium is certainly accepted here, the challenges of establishing causation for organizational change make this definition a problematic one. How are we to identify some environmental forces as turbulence and others as perturbance when organizations (and the individuals within them) are responding in complex ways to the entire internal and external milieu all at once? It is difficult to push this area of study if we are bound to this definition of perturbance as a type of turbulence that has a certain result (disequilibrium). This is like calling a baseball pitch a home run when it is halfway between the pitcher's mound and home plate. Until the outcome is known, we can really just call it a pitch. Likewise, a force acting on a school with unknown outcome is just that, a force.

What I propose instead is that perturbance is recast to refer to the process in which a system takes up a perceived disruptive force (turbulence) and considers - at the group level - the fit between environmental needs and organizational practice. Hence, perturbance follows turbulence chronologically. Even in the intentional self-turbulence found at Sears and in Freire's literacy lessons in Brazil, the initial convening of people does not constitute perturbance because is not yet considering organizational actions and purposes with respect to the environment. These collective exercises produce turbulence as specific areas of concern and dissatisfaction arise. When an issue is arrived at and recognized as legitimate by the group, organizational turbulence is then created, and the group can work through this and decide "what's next" (perturbance) or choose to leave things as they are.

\section{Perturbance in nested systems}

The sanctions presented by the No Child Left Behind Act and the Race to the Top for underperforming schools in the USA operate on the assumption that both structural and cultural collapse of poor performing schools will lead to long-term system improvement. As these laws and policies are enacted, schools face increased pressure to raise achievement scores or face closure or reconstitution. So the theory goes, policies generated in Washington or in the state capitals then have significant power to alter practice at the school and even classroom levels. 
Given this use of intentional turbulence as a state-level change strategy, it seems appropriate therefore, to look at turbulence operating differently on different levels of a nested system (Carr, 1997; Hutchins, 1996). Intentional turbulence is usually initiated by a higher level of an organization (national, state) in hopes that change will occur at the lower level (district/school) ${ }^{1}$. But turbulence does not have equivalent effects on different levels of a system. We must be careful not to assume that turbulence initiated at the state level will necessarily lead to the helpful perturbances we would like to see at the school level. Educational change operates across many levels of systems (individual students and teachers, whole schools, districts, entire communities, states, etc.) and examining a reform's interactions with only one level of the system is unlikely to give a clear picture of what is changing or not and why (Muncey \& McQuillan, 1996). As an example, post-Katrina changes in New Orleans public schools take on a very different character depending on whether one is looking at the state level and/or individual school level. From one frame (that of the state), Katrina can be seen, quite reasonably, as an ideal turbulence to alter the practice of schooling in this historically low-performing school system. State legislators voted on legislation that led to state takeover of most public schools in the city, paving the way for improvement. But from another frame (that of school principals and teachers) Katrina hindered change much more than it acted as a catalyst. Teachers had little time to attend to professional learning as their homes were being repaired. They faced extreme challenges in meeting the socialemotional needs of traumatized students while state accountability pressures never let up (Beabout, 2010). To use Gross' airplane analogy (1998), what was a big bump at the state level was a total crash with only a few survivors at the school level. This is in line with Drucker's comment that in times of turbulence, "first-line supervisors may face the most upsetting challenges, for which they are least prepared" (1980, p. 226). This idea of differential perturbance in nested systems buttresses the idea that schools are complex human systems that cannot be understood from only one or two perspectives. This necessitates the inclusion of multiple perspectives in a process of perturbance characterized by a slow pace, collaborative trust, and solving shared problems. It also should give us pause when pursuing intentional turbulence as a change strategy.

\section{Conclusion}

Perturbance, defined as a social process of examining its goals and practices, can be an important component in the process of sustainable educational change. If schools are to develop as learning organizations, then change will always require individuals to come together and re-examine the goals of their school and how current practices serve to meet them. Turbulence, defined as the perception of forces with the potential to impact a school, can be a useful catalyst to perturbance. Turbulence can raise awareness, build commitment, and spawn imaginative thinking and practice. But there exists an upper limit to turbulence if schools are to engage in sustainable change. If turbulence is so great that essential change activities such as collaborative learning and decision making, collection and analysis of shared data, and a re-examination of goals and purposes are not enacted, then the only types of changes likely to be successful are mandates from powerful authorities, or prepared interest groups, which have a long and unimpressive history in much of Western schooling (Ravitch, 2000). For sustainable change to occur, environmental turbulence must be of only moderate degree, and opportunities for perturbance to occur must be fostered by building collaborative cultures (Hargreaves, 1994) rather than tearing schools apart and rebuilding them from scratch.

\footnotetext{
${ }^{1}$ Educational activism can be described as causing intentional turbulence upward toward higher levels of the system, and recent scholarship in this area has been generated by Evans (2011), Fabricant (2010), and Warren and Mapp (2011).
} 


\section{References}

Alhadeff-Jones, M. (2008). Three generations of complexity theories: Nuances and ambiguities. Educational Philosophy and Theory, 40(1), 66-82.

Beabout, B.R. (2007). Stakeholder organizations: Hurricane Katrina and the New Orleans Public Schools. Multicultural Education, 15(2), 43-49.

Beabout, B.R. (2010). Leadership for change in the educational wild-west of post-Katrina New Orleans. The Journal of Educational Change, 11(4), 403-424.

Berman, P., \& McLaughlin, M. (1975). Federal programs supporting educational change, Vol. 1: A model of educational change. Santa Monica, CA: RAND.

Briggs, J., \& Peat, F.D. (1999). Turbulent Mirror: An illustrated guide to chaos theory and the science of wholeness. New York: Harper and Row.

Bryk, A.S., \& Schneider, B. (2002). Trust in schools: A core resource for improvement. New York: Russell Sage Foundation.

Buras, K.L. (2010). Pedagogy, policy, and the privatized city: Stories of dispossession and defiance from New Orleans. New York: Teachers College Press.

Carr, A.A. (1997). User design in the creation of human learning systems. Educational Technology Research and Development, 45(3), 5-22.

Carr-Chellman, A.A. (2000). The new sciences and systemic change in education. Educational Technology, 40(1), 28-37.

Chang, C. (2010). RSD chief gets earful on charters. Retrieved April 9, 2010, from http: / / www.nola.com

Chesler, M.A., Crowfoot, J.E., \& Bryant, B.I. (1980). Using institutional conflict to achieve change in schools. In M.M. Milstein (Ed.), Schools, conflict, and change (pp. 30-49). New York: Teachers College Press.

Christensen, C.M. (1997). The innovator's dilemma: When new technologies cause great firms to fail. Boston, MA: Harvard Business School Press.

Cuban, L. (2001). Oversold and underused: Computers in the classroom. Cambridge, MA: Harvard University Press.

Davis, B. (2008). Complexity and education: vital simultaneities. Educational Philosophy and Theory, $40(1), 50-65$.

Datnow, A. (2011). Collaboration and contrived collegiality: Revisiting Hargreaves in the age of accountability. The Journal of Educational Change, 12(2), 147-158.

Drucker, P. (1980). Managing in turbulent times. New York: Harper and Row.

Duffy, F.M. (2003). Step-Up-To-Excellence: An innovative approach to managing and rewarding performance in school systems. Lanham, MD: ScarecrowEducation.

Elmore, R.F., \& Burney, D. (1999). Investing in teacher learning: Staff development and instructional improvement. In L. Darling-Hammond \& G. Sykes (Eds.), Teaching as the learning profession: Handbook of policy and practice (pp. 236-291). San Francisco: Jossey-Bass.

Ely, D. (1976). Creating the conditions for change. In S. Faibisoff \& G. Bonn (Eds.), Changing times: Changing libraries (pp. 150-162). Champaign, IL: University of Illinois Graduate School of Library Science.

Emery, F.E., \& Trist, E.L. (1965). The causal texture of organizational environments. Human Relation, $18,21-31$.

Evans, M.P. (2011). Learning to organize for educational change: One CBO's efforts to influence educational policy. In C.M. Hands \& L. Hubbard (Eds.), Including families and communities in urban education (pp. 139-160). Charlotte, NC: Information Age Publishing.

Evans, R. (1996). The human side of school change. San Francisco: Jossey-Bass.

Fabricant, M.B. (2010). Organizing for educational justice: The campaign for public school reform in the South Bronx. Minneapolis: University of Minnesota Press.

Fink, D. (2003). The law of unintended consequences: The 'real' cost of top-down reform. Journal of Educational Change, 4(2), 105-128.

Freire, P. (2000). Pedagogy of the oppressed (M.B. Ramos, Trans. 30 ${ }^{\text {th }}$ Anniversary ed.). New York: Continuum.

Friedman, M. (1962). Capitalism and freedom. Chicago, IL: University of Chicago Press.

Fullan, M. (1999). Change forces: The sequel. London: Falmer Press.

Fullan, M. (2000). The three stories of education reform. Phi Delta Kappan, 81(8), 581-584.

Fullan, M. (2001). Leading in a culture of change. San Francisco: Jossey-Bass.

Gross, S.J. (1998). Staying centered: Curriculum leadership in turbulent times. Alexandria, VA: Association for Supervision and Curriculum Development. 
Gross, S.J. (2004). Promises kept: Sustaining school and district leadership in a turbulent era. Alexandria, VA: Association for Supervision and Curriculum Development.

Hargreaves, A. (1994). Changing teachers, changing times: Teachers' work and culture in the post-modern age. New York: Teachers College Press.

Hargreaves, A., \& Shirley, D. (2008). Beyond standardization: Powerful new principles for improvement. Phi Delta Kappan, 90(2), 135-143.

Harris, D. (2010). The evidence on race to the top. Retrieved April 9, 2010, from http:/ / www.edweek.org

Hubbard, L., Mehan, H., \& Stein, M. K. (2006). Reform as learning: School reform, organizational culture, and community politics in San Diego. New York: Routledge.

Hutchins, C.L. (1996). Systemic thinking: Solving complex problems. Aurora, CO: Professional Development Systems.

Jörg, T. (2009). Thinking in complexity about learning and education: A programmatic view. Complicity: An International Journal of Complexity and Education, 6(1), 1-22.

Klein, N. (2007). The shock doctrine: The rise of disaster capitalism. New York: Metropolitan Books.

Lemke, J.L., \& Sabelli, N.H. (2008). Complex systems and educational change: Towards a new research agenda. Educational Philosophy and Theory, 40(1), 118-129.

Little, J.W. (1990). The persistence of privacy: Autonomy and initiative in teachers' professional relations. Teachers College Record, 91(4), 509-536.

Lortie, D. (1975). School teacher: A sociological study. Chicago: University of Chicago Press.

Mainzer, K. (1999). Thinking in complexity: A new paradigm for learning. Complicity: An International Journal of Complexity and Education, 6(1), 23-27.

Mason, M. (Ed.). (2008). Complexity theory and the philosophy of education. West Sussex, UK: WileyBlackwell.

Maxcy, S.J. (1995). Democracy, chaos, and the new school order. Thousand Oaks, CA: Corwin Press.

McLaughlin, M. (1990). The rand change agent study revisited: Macro perspectives and micro realities. Educational Researcher, 19(9), 11-16.

McLaughlin, M.W., \& Mitra, D. (2001). Theory-based change and change-based theory: Going deeper, going broader. Journal of Educational Change, 2(4), 301-323.

McLaughlin, M.W., \& Talbert, J. (2001). Professional communities and the work of high school teaching. Chicago: University of Chicago Press.

McQuillan, P.J. (2008). Small-school reform through the lens of complexity theory: It's "good to think with". Teachers College Record, 110(9), 1772-1801.

Meier, D. (2002). The power of their ideas ( $2^{\text {nd }}$ ed.). Boston: Beacon Press.

Milstein, M.M. (Ed.). (1980). Schools, conflict, and change. New York: Teachers College Press.

Morin, E. (1999). Seven complex lessons in education for the future. Paris: United Nations Educational, Scientific, and Cultural Organization (UNESCO).

Morrison, K. (2002). School leadership and complexity theory. London: RoutledgeFalmer.

Muncey, D.E., \& McQuillan, P.J. (1996). Reform and resistance in schools and classrooms: An ethnographic view of the Coalition of Essential Schools. New Haven: Yale University Press.

Nathan, L.F. (2009). The hardest questions aren't on the test: Lessons from an innovative urban school. Boston, MA: Beacon Press.

Newmann, F.M., \& Wehlage, G.G. (1995). Successful school restructuring. Madison, WI: Center on Organization and Restructuring of Schools.

Nias, J., Southworth, G., \& Campbell, P. (1992). Whole school curriculum development in the primary school. Lewes: Falmer Press.

Oakes, J., \& Lipton, M. (2002). Struggling for educational equity in diverse communities: School reform as social movement. Journal of Educational Change, 3(3-4), 383-406.

Olsen, B., \& Kirtman, L. (2002). Teacher as mediator of school reform: An examination of teacher practice in 36 California restructuring schools. Teachers College Record, 104(2), 301-324

Osberg, D. (2005). Redescribing 'education' in complex terms. Complicity: An International Journal of Complexity and Education, 2(1), 81-83.

Pascale, R.T., Millemann, M., \& Gioja, L. (2000). Surfing on the edge of chaos: The laws of nature and the new laws of business. New York: Three Rivers Press.

Perry, A.M., \& Schwam-Baird, M.M. (2010). School by school: The transformation of New Orleans public education. Washington: Brookings Institution and Greater New Orleans Community Data Center.

Peshkin, A. (1978). Growing up American: Schooling and the survival of community. Prospect Heights, IL: Waveland Press.

Polley, D. (1997). Turbulence in organizations: New metaphors for organizational research. Organization Science, 8(5), 445-457.

Prigogine, I., \& Stengers, I. (1984). Order out of chaos: Man's new dialogue with nature. Boulder, CO: New Science Library. 
Ravitch, D. (2000). Left back: A century of failed school reform. New York: Simon and Schuster.

Ravitch, D. (2010). The death and life of the great American school system: How testing and choice are undermining education. New York: Basic Books.

Reigeluth, C.M. (2004, April). Chaos theory and the sciences of complexity: Foundations for transforming education. Paper presented at the American Educational Research Association, San Diego, CA.

Reigeluth, C.M. (2006). A leveraged emergent approach to systemic transformation. Tech Trends, 50(2), 46-47.

Reigeluth, C.M., Carr-Chellman, A.A., Beabout, B., \& Watson, W. (2006). Creating shared visions of the future for K-12 education: A systemic transformation process for a learner-centered paradigm. The Journal of Educational Alternatives, 3(1), 34-66.

Sarason, S. (1982). The culture of the school and the problem of change ( $2^{\text {nd }}$ ed.). Boston: Allyn and Bacon.

Sarason, S. (1990). The predictable failure of educational reform. San Francisco: Jossey-Bass.

Selsky, J.W., \& McCann, J.E. (2008). Managing disruptive change and turbulence through continuous change thinking and scenarios. In R. Ramirez, J.W. Selsky and K. Van der Heijden (Eds.), Business planning for turbulent times: New methods for applying scenarios (pp. 167-186). London, UK: Earthscan.

Senge, P.M. (1990). The fifth discipline: The art and practice of the learning organization. New York: Doubleday.

Senge, P.M. (2000). Schools that Learn: A Fifth Discipline Fieldbook for Educators, Parents, and Everyone Who Cares about Education. New York: Random House.

Sirotnik, K. (2005). Ecological images of change: Limits and possibilities. In A. Lieberman (Ed.), The roots of educational change (pp. 181-197). Dordrecht, Netherlands: Springer.

Stein, M.K., Hubbard, L., \& Mehan, H. (2004). Reform ideas that travel far afield: The two cultures of reform in New York City's District \#2 and San Diego. Journal of Educational Change, 5(2), 161-197.

Tye, B.B. (2000). Hard Truths: Uncovering the deep structure of schooling. New York: Teachers College Press.

Warren, M.R., \& Mapp, K.L. (2011). A match on dry grass: Community organizing as a catalyst for school reform. New York: Oxford University Press.

Wheatley, M.J. (1999). Leadership and the new science: Discovering order in a chaotic world (2 ${ }^{\text {nd }}$ ed.). San Francisco: Berrett-Koehler.

\section{About the Author}

Brian R. Beabout is an Assistant Professor at the University of New Orleans. He is a former high school teacher with research interests in educational change, urban education, and leadership. He is a member of the editorial review board for the School Community Journal. His work is published in the Journal of Thought, The Journal of Educational Change, The Journal of Education for Students Placed At-Risk, Multicultural Education, and The International Journal of Educational Reform. He was a founding board member of the Morris Jeff Community School in New Orleans and can be reached at bbeabout@uno.edu.

(c) Copyright 2012. The author, BRIAN R. BEABOUT, assigns to the University of Alberta and other educational and non-profit institutions a non-exclusive license to use this document for personal use and in courses of instruction provided that the article is used in full and this copyright statement is reproduced. The author also grants a non-exclusive license to the University of Alberta to publish this document in full on the World Wide Web, and for the document to be published on mirrors on the World Wide Web. Any other usage is prohibited without the express permission of the author. 